\title{
SARMIENTO EN ESPAÑA Y ESPAÑA EN SARMIENTO
}

Oscar TACCA

El título implica una falsa simetria. Sarmiento estuvo solamente dos meses y medio en España, mientras que España estuvo incesantemente en la vida de Sarmiento: fue a un tiempo su demonio, su numen, su obsesión.

Por de pronto, la llevaba en su sangre. Descendia de los primeros colonizadores de Chile y Argentina. Era asi por vía paterna (los Quiroga Sarmiento) y podia haber algún origen árabe por vía materna (los Albarracín); sin excluir una gota de sangre huarpe. La llevaba, además, en su lengua, como sino inexorable, que sería permanente objeto de impugnación. Pero la llevaba sobre todo -constante motivo de protesta y rebeldia- en su atavismo, en su educación y en las ideas y costumbres heredadas.

Desde muy joven empezó a hurgar en lo que podia ser el principio y causa de nuestros males. En medio de una sociedad dividida y enfrentada, de anarquía primero y tirania después, frente al modelo de paises más civilizados y orgánicos, Sarmiento comienza a ver nuestros males y defectos como resultado de nuestra herencia. El examen de España es severo y despiadado:

Veo siempre la antigua España, viva todavia en nuestros corazones, en nuestros hábitos, en nuestras tendencias; la veo en la ignorancia y en la superstición de nuestras masas; en la resistencia que de todas partes se levanta; en los obstáçulos con que tenemos que luchar, en la tendencia al despotismo de la generalidad de nuestros gobiernos americanos; en la indolencia de los gobernados; en su falta de espíritu público; en todo, en todas partes veo siempre la sombra de ese genio maléfico.

(V1 72) ('1)

La imagen filial será constante: somos hijos de esa España:

Yo no veo en nuestros males, en nuestras desgracias, sino el genio ominoso que ha presidido a aquella desventurada nación, y el alma que comunicó a sus hijos en América. (ibid.)

Pero hasta los treinta y cuatro años, Sarmiento no ha salido de estas tierras, y va a ser entonces cuando (con motivo de la misión encomendada por el Ministro Montt de Chile, donde a la sazón se encontraba exiliado) emprenderá viaje a Europa. La travesía lo lleva a Francia, y después de cinco meses alli, Sarmiento va a encontrarse (¿a re-encontrarse?) con España.

Si un viaje supone cierta preparación (o disposición favorable) la de Sar- 
miento no podía ser peor. Tenía todos los pre-juicios (en ambos sentidos) que se pueda imaginar. Tanto geográficos:

(...) la España, esa rezagada de Europa, que echada entre el Mediterráneo y el Océano, entre la edad media y el siglo XIX, unida a la Europa culta por un ancho Istmo, y separada del Africa bárbara por un angosto Estrecho ...

(VII 7)

como históricos:

Por sus costumbres y su espíritu, el pueblo español es el pueblo más romano que existe hoy día. Todos sus males le vienen de ahi; enemigo del trabajo, guerrero, heroico, tenaz, sobrio, y apasionado por los espectáculos, todavía pide panem et circenses para vivir feliz en medio de su caída.

como culturales:

La España aún no está libre hoy de esa cadena que ha pesado sobre su cuello durante siglos: privada por la Inquisición y el despotismo de participar del movimiento de ideas que con el Renacimiento habia principiado en todos los otros pueblos; dominada entonces por ese mismo odio a todo lo que era libre y repugnaba con su unidad católica y su reconcentración despótica, que muestran los celosos partidarios de la imposible incolumidad de la lengua, quedóse sola en Europa y renunció a su poder marítimo, terrestre, literario y científico.

(1 217)

Iba prevenido, intelectual y moralmente. Algo de esto lo reconocía, pues en el umbral mismo de sus impresiones declara que, teniendo por fin a España "en el anfiteatro, bajo la mano; la palpo ahora, le estiro las arrugas, y si por fortuna me toca darle con los dedos sobre una llaga a fuer de médico, aprieto maliciosamente la mano para que le duela, como aquellos escribanos de los tribunales revolucionarios o de la inquisición de antaño, que de las inocentes palabras del declarante sacaban por una inflexión de la frase el medio de mandarlo a la guillotina o a las llamas" ( 147$)$. No obsta para que a renglón seguido invoque imparcialidad de juicios, "que nada tienen de prevenidos".

Pero si bien es cierto que tenía ya opiniones definidas y juicios establecidos, es probable que su prevención, o más bien animadversión, se hubiese acentuado en la -todavia reciente- diatriba con el Sr. Minvielle, sobre la cual volveremos. Sea como fuere ésta había servido, pocos meses antes, para exacerbar la hispanofobia de Sarmiento. Es alli donde se encuentran las más duras invectivas contra España.

Entró en la península por el paso de Bayona a Irún, el 3 de octubre de 1846. Reinaba en España la adolescente Isabel II (casada con el débil e impotente duque de Cádiz, Francisco de Asis Maria de Borbón, doblemente primo hermano de ella), entre los vaivenes y las presiones de ministros y favoritos (Istúriz, Serrano el general bonito, Benavides, Salamanca, Narváez) pero sobre todo entre las luchas e influencias de moderados y progresistas.

Hoy podemos seguir su itinerario con el seguro testimonio de sus "cartas" y del invalorable "diario de gastos" que llevara. Ya el carruaje que lo 
trasladaba es motivo de asombro y comparación con lo que ha visto (o supone) de Europa:

La diligencia es tirada por ocho pares de mulas puestas el tiro de dos en dos, a veces por diez pares en donde el devoto repasándolas con la vista podria rezar su rosario; negras todas, lustrosas, tusadas, rapadas, taraceadas, con grandes plumeros carmesí sobre los moños, y testeras coloradas, y rapacejos y redes y borlas que se sacuden al son de cien campanillas y cascabeles; animado este extraño drama por el cochero, que en traje andaluz y con chamarra árabe, las alienta con una retahila de blasfemias a hacer reventar en sangre otros oídos que los españoles; con aquello de jarre p... marche la Zumalacarregui, anda... de la Virgen, ahi está el carlista... p..., Cristina janda, jandaaal y Dios, y los santos del cielo y las potestades del infierno entran pêle-mêle en aquella tormenta de zurriagazos, pedradas, gritos y obsenidades horribles".

El estilo, sin duda, es sarmientino.

( 1 149)

No registró casi impresiones del país vasco. El viandante que lo atraviesa "apenas si observa una población pasablemente atrasada que coge castañas en los bosques, siembra maíz y patatas, y vive tranquila en sus montañas sin placeres como sin penas. De tiempo en tiempo se avistan las tostadas ruinas de alguna aldea, saqueada, quemada y arrasada durante la guerra de los carlistas. ¡Qué horrores revelan estos vestigios! ¿Qué de crueldades inauditas han sido cometidas en estos lugares!". "Pero el viajero que va arrastrado por la diligencia -anota- no detiene por lo general su pensamiento ni sobre lo pasado ni sobre el porvenir de este pais". Es lo que Sarmiento hace: Repasa algunos datos históricos y sociales, para referirse en particular a los problemas que las reivindicaciones regionales y politicas planteaban, especialmente la implantación del control aduanero, enemigo de la libertad comercial. En suma, para señalar el "destiempo" de España:

... cuando todas las naciones de la Europa estaban encorvadas bajo el yugo del despotismo, los españoles tenian en el Aragón sus célebres cortes, donde decian al rey sin quitarse el sombrero en su presencia: "nosotros que valemos tanto como vos, y que podemos más que vos, os instituimos nuestro rey y señor"; pero cuando la Europa se agitó para obtener un poco de libertad, la España inventó con un admirable apropósito las instituciones inquisitoriales. Ahora que el comercio libre hace prosélitos por todas partes, fuerza a la Vizcaya, que había conservado intacta la tradición adámica, a admitir la aduana en su territorio.

(V 152) describe:

La travesía de Castilla le mereció más atención. Con pocos trazos la

La Castilla vieja es todavia una pradera inmensa en la que 
pacen numerosos rebaños, de ovejas sobre todo. La aldea miserable que el ojo del viajero encuentra, se muestra a lo lejos terrosa y triste; árbol alguno abriga bajo su sombra aquellas murallas medio destruidas, $y$ en torno de las habitaciones, la flor más indiferente no alza su tallo, para amenizar con sus colores escogidos la vista desapacible que ofrecen llanuras descoloridas, arbustillos espinosos, encinas enanas y en la lontananza montañas descarnadas y perfiles adustos. $\quad$ (V 150)

Llegó a Burgos de noche. Las observaciones muestran cómo Sarmiento va enlazando reflexiones en una imprevisible cadena sin cesurás. La oscuridad nocturna le hace ver los monumentos, especialmente la catedral, con "algo de vago y misterioso", confiriéndoles poesía y pintoresquismo. Pero augura que, "al paso que van las cosas en España", esos caracteres pronto habrán desaparecido, como han desaparecido "aquellos monjes blancos, pardos, chocolates, negros, overos, calzados y descalzos, que hicieron la gloria del paisaje español hasta 1830", dando lugar al espectáculo más triste y miserable de los frailes, los ciegos y mendigos. Estos últimos, con su raida indumentaria hecha casi toda de remiendos. Los que son, a su vez, para Sarmiento, el símbolo del sistema aplicado en España durante los últimos tiempos a las reformas políticas y sociales: "En lo moral o en lo físico no conozco pueblo más remendado, sin contar todos los agujeros que aún le quedan por tapar". Y esto, a su vez, le parece justificar que haya espiritus descontentos que vean, como un remiendo más, el casamiento de Isabel II.

Estuvo en Madrid algo más de un mes. Su estada coincidió con los festejos de las bodas simultáneas de Isabel II (abolida la ley sálica) y de su hermana María Luisa Fernanda con los duques de Cádiz y Montpensier, respectivamente, de las que registrara extensamente (en carta a su amigo Lastarria) la fastuosidad del cortejo real por la engalanada calle de Alcalá, la bendición nupcial en la iglesia de Atocha y las fiestas populares que duraron varios dias. Fue al teatro, asistió a tertulias literarias en los cafés de moda, concurrió a las corridas de toros, sin que faltara alguna escapada nocturna que en su diario consigna con la púdica abreviatura de org. (ia). Visitó el Escorial que le mereció, más que admiración, repulsa. Todo fue objeto de crónica puntual, salpicada de largos comentarios en los que observa y juzga tipos, costumbres, modas, diversiones. Dedicó largas páginas al espectáculo taurino, que le provocaba a un tiempo fascinación y rechazo: su sensibilidad lo exalta, su inteligencia lo condena. "He visto los toros, y sentido todo su sublime atractivo. Espectáculo bárbaro, terrible, sanguinario, y sin embargo, lleno de seducción y estímulo" (¿seducción de la barbarie?). Algo, empero, no podia estar en él ausente, por su raíz criolla: la verdadera víctima del toreo era el caballo, por el que Sarmiento, muy buen jinete siempre sintió veneración y afecto. La corrida era para él pariente próximo, por un lado (obviamente) del circo romano, y por otro (menos obviamente) de la Inquisición: "en España los autos de fe y los toros anduvieron siempre juntos" (V 170). Barbarie que, sostenía, también hemos heredado: 
Este pueblo asi educado, es el mismo que se ha abandonado a las espantosas crueldades de la guerra de cristinos y carlistas en España, el mismo que a orillas del Plata, se ha degollado entre sí con una barbaridad, con un placer, diré más bien, que sobrevive hoy en la raza española; porque no ha de conservarse un espectáculo bárbaro, sin que todas las ideas bárbaras de las bárbaras épocas en que tuvieron origen vivan en el ánimo del pueblo. Es para mi el hombre un animal antropófago de nacimiento que la civilización está domesticando, amansando, de cuatro o cinco mil años a esta parte; y ponerle sangre a la vista, es sólo para despertar sus viejos y adormecidos instintos:

( 170$)$

A las fiestas al aire libre se unian las representaciones teatrales. Con tal motivo, desdeña un teatro que persistia en el convencionalismo de reglas y unidades, de manifestación en verso, inadecuado para el drama de actualidad que exigia libertad, ruptura, audacia de concepción, es decir, un cambio semejante al que por entonces se producía. en Francia con autores como Hugo o Dumas. Insuficiencias que le sirven para reivindicar la novela, el género más apto, a su juicio, para expresar ese drama ("la novela, el folletín, verdaderas epopeyas de nuestro siglo") y comprobar su escasez y pobreza en nuestras letras, debido a la estrechez de ambiente del autor y simplicidad de la sociedad, que "estorban la aparición de la novela en España lo mismo que en América". (2)

De modo semejante, la pintura y escultura que pudo contemplar en el Prado le merece juicios excesivos ("No hay estatuas en España", Rivera, Velázquez "son los pintores de la España que se petrificó en el Escorial") por su misma prevención.

Partió de Madrid hacia Andalucia, pasando por Aranjuez, Ocaña, Valdepeñas (sin detenerse). La Mancha evoca en él, naturalmente, el recuerdo de Cervantes, y son los olivares la única nota del paisaje. Un retraso de la diligencia opuesta lo demora, aguarda con los demás viajeros durante la noche, la velada se puebla de relatos de asaltos y bandidos. Entre tales relatos oye el de una madre e hija que, para robarle, asesinan a un viajero al que alojaran, quien resulta ser hijo y hermano de ellas (y cuya trama, como se ve, es igual a la del Malentendu de Camus). Sarmiento cuenta que niega en la tertulia su veracidad, por reconocer en él a otro idéntico, escuchado antes y localizado en nuestra Córdoba (3). El ruido de la diligencia les devuelve la calma, y a media noche emprenden nuevamente viaje rumbo a Córdoba.

La entrada en Andalucia es motivo para oponerla, como la Bética, latina, alegre, fértil, a la lberia y la Lusitania, y recordar con elogio la figura de Carlos III.

La visita de Córdoba y Sevilla significan, de hecho, el primer encuentro efectivo de Sarmiento con el mundo árabe, o con lo que de él sobrevivía en España. Conocido es el respeto, muchas veces la admiración y a menudo la comparación del mundo árabe con el del gaucho.

Por el Gadalquivir llegó a Cádiz en un vapor inglés. De Cádiz, en un vapor francés fue a Gibraltar, y de alli por el mar Mediterráneo hasta Valencia. 
Quedó asombrado ante los huertos prolijamente cultivados e irrigados, "como lo enseñaran los moros", los tejidos de las mantas que le récuerdan los de nuestra Córdoba, y -no podia faltar en él, siempre sensible al encanto femenino- la gracia de las mujeres andaluzas:

(...) graciosas como bayaderas, locas por el placer como las orientales, y aquel pueblo que canta todo el dia, rie, riñe y miente 'con un' aplomo que asombra. ¡Oh! las hipérboles andaluzas dejarian atónitos a los más hiperbólicos asiáticos. ¡Qué imaginación, qué riquezas de espiritu! ¡Qué feliz es la alegre Andalucia!

(V 188

Antes de proseguir su viaje a Cataluña hace un breve alto de revisión histórica, como una sintesis retrospectiva necesaria a su permanente afán de ordenamiento y claridad: Tiempos primitivos, Tiempos romanos, Tiempos árabes, Tiempos inquisitoriales y Tiempos modernos.

Llegó en diligencia a Barcelona: "Estoy, por fin, fuera de la España". El país catalán le mereció elogios, como era de esperarse, por su carácter más europeo. Fue, como de costumbre, categórico: "otra sangre, otra estirpe, otro idioma". Conoció a Cobden, el gran agitador inglés de aquel tiempo, que le brindó amistad, lo cautivó. Cruzó a Mallorca. De regreso, se hizo tiempo para pasear por la Rambla, visitar el teatro Nuevo de Barcelona y preparar su pasaporte.

Salió de España con el mismo espiritu crítico con que entrara. Le quedaban, sin que él mismo lo supiera, impresiones sensoriales y mentales que obrarian en su memoria y en su pensamiento por el resto de su vida.

Todos los paises tienen motivos de dolor, vergüenza, mortificación, arrepentimiento. No le faltan a España. Cada individuo los vive a su manera. Menos aquellos que han decidido ocultarlos o negarlos, ante si, pero sobre todo, ante los otros. Hay, por el contrario, quienes los viven hondamente, conflictivamente, de manera personal, como un drama incesante, como un disconformismo raigal: son la conciencia viva, admonitoria, lacerante del pais. Los primeros han construido un infierno, al que han arrojado a los segundos, presuntos incursos en el nefando pecado de antiespañolismo: Quevedo, Cadalso, Larra, Clarín, Ortega, Cernuda, Goytisolo, Vicent... A hacerle buena compañia (si no se necesitara carta de ciudadanía, por lo demás, celosamente custodiada) habrian lanzado de buen grado a Sarmiento.

Este no hurgó en la realidad española por ella misma. Lo hizo en cambio permanentemente en su relación con la nuestra, y con la de toda la América española. Atribuia la mayoria de sus males, de manera casi obsesiva, al patrimonio heredado. Pero no era contra la sangre ni contra el pueblo que se revelaba. Lo precisó algunas veces:

Para mi, como para todos los americanos, la palabra España representa más una idea que un pueblo.

Subrayó las semejanzas, aunque a menudo fueran más motivo de queja que de entusiasmo:

Nunca vi hombres ni pueblos que se parezcan más eñtre si que los que hablan la lengua castellana.

(XXIX 253) 
La América española es más española que la España misma; no obstante que una y otra están empeñadas en probar lo contrario, a cañonazos, o incendiando ciudades.

(XXIX 202)

Todos, jóvenes o viejos, americanos y aún peninsulares, están cortados por un mismo padrón. El mismo sentimiento de importancia como naciones; la misma idea de la superioridad relativa si son americanos, sobre los de allende los mares; los mismos celos y predisposición a odiarse y menospreciarse recíprocamente los de una sección con los de otra.

(XXIX 253)

Procuró a veces restituir un aprecio y estima que no podia dejar de sentir en su raiz. El lector advierte en sus escritos, alternativamente, una de cal y otra de arena, el respeto y la denuncia, el reconocimiento y la condena, aunque haya mucho más de esto que de aquello.

¿Qué valores o virtudes apreciaba más en los españoles?. Fundamentalmente, el coraje, la franqueza, la honradez, la sobriedad, la hidalguía, la hospitalidad. Esa tenue hispanofilia no eclipsa sin embargo la hispanofobia. Muchos de los males que denunciara (ácidamente) habian sido o serían señalados, antes y después, como sabemos, también por otros extranjeros o españoles. ¿Cuáles eran para Sarmiento los temas, motivos o caracteres, blanco de sus dardos, en suma, las recriminaciones capitales?.

ignorancia:

[...] cuando la mano de la libertad ha venido a despertarla en nuestros tiempos, como despertó a sus colonias, halló a la madre y a las hijas en la miseria y en la ignorancia, sin tradiciones, sin arte y sin ideas.

Asi la España, por odio a los extranjeros, se quedó encerrada en su Penisula; [...] ignorante, cuando su antigua literatura habia ido a inspirar la de otras naciones.

Todo lo que ha pasado de docientos años a esta parte en el mundo científico e intelectual, es poco más o menos como no ocurrido para este pueblo, cuyo genio fecundo y original habria podido contribuir poderosamente a los progresos del espíritu humano y de la civilización en general. En lugar de esto nada hay en Europa que iguale su apatía y su ignorancia, y tan fuera del movimiento intelectual que comenzó en el siglo XVI ha permanecido, que ni un solo español se ha creado un nombre en las matemáticas, la astronomía, la física, la química, la fisiología, la medicina, la filosofía; en una palabra, en ningún ramo de la ciencia.

(Lamenais)

[La Comunidad hispánica] muestra que todavia se encuentra en posición receptiva -o sea, pasiva- , tal cual lo había venido estando durante los tres últimos siglos, frente a los avances de la ciencia, tanto pura como aplicada, cuyos frutos le llegan importados de otras zonas de nuestra civilización. Aún no está demasiado lejos, y a mi por mi edad me ha tocado presenciarla, 
aquella curiosa discusión acerca de si el hombre hispano posee o no aptitud para la ciencia, una polémica cuya manifestación más chocante fue el exasperado grito unamuniano: "QQue inventen ellos!", dejando a los demás miembros de la civilización moderna la tarea de promover el progreso material.

(Francisco Ayala, "El descubrimiento de América, hoy", en La Nación, Bs.As., 17-11-91)

atraso:

El odio a lo extranjero de los españoles, es la clave de toda su historia, de sus calidades heroicas, de su aislamiento de la Europa y de su atraso.

Un crecido número de emigrantes de otras naciones que no sean la española, la única que nos es análoga en atraso intelectual $e$ incapacidad industrial [...]

En España acaso por su forma peninsular, y ser los Pirineos malos conductores de ideas, que rechazan tradiciones moriscas, retardan de un siglo los progresos humanos. (XLII 266)

En España continuó la edad media que se difundió y estableció en Amërica.

(XXXVIII 192)

despotismo:

Españoles y americanos comprenden por la España el antiguo y doble despotismo que hizo de ella una excepción de la Europa $[\ldots]$

(IV 62)

Yo añadiria a estas tristes verdades las de Mac Gregor su odio a los extranjeros, sus celos de provincia, su falta de respeto porla propiedad y la vida,su tolerancia del despotismo [...] (VI 268)

[...] con la expulsión de los moros perdió su industria y su agricultura; con la de los judios, su dinero y su comercio; con la inquisición, armó a sus reyes del despotismo más absoluto, dándoles derecho de penetrar con el Santo Oficio en el hogar doméstico, destruyendo así todas las garantias que resguardan al ciudadano.

(IX 283)

\section{Inquisición:}

[...] privada por la Inquisición y el despotismo de participar del movimiento de ideas que con el Renacimiento habia principiado en todos los otros pueblos [...] quedóse sola en Europa y renunció a su poder marítimo, terrestre, literario y científico.

[...] desnuda de ideas y de vestido, se envolvia en su roto manto y calentaba sus manos ateridas en las hogueras de la inquisición, encendidas para abrasar en ellas las ideas que se desenvolvian en el extranjero.

(1 229) 
La forma peninsular de la España,los Pirineos del lado del continente, la hacen inaccesible a las ideas, como ciertas materias que son mal conductoras del calor, y retienen largo tiempo el propio. A esta causa accesoria se debió que se estableciese sólidamente la Inquisición, y que durase tres siglos, no obstante haber asumido otras formas la opinión en Europa. (XXXVIII 330)

aislamiento:

Por esta prevención nacional contra lo extranjero, que es común a todas las naciones, pero que en el corazón de los españoles se exaltó hasta convertirse en un vicio radical por efecto de aquella larga lucha (contra los árabes), la España se puso en pugna con todas las naciones europeas; y mientras las demás se civilizaban, senriquecian por los descubrimientos y adelantos de las ciencias, ella se bloqueó contra las ideas de Europa [...]

La España cerró sus colonias a todos los hombres de otra estirpe, idiome y creencia que la suya propia [...]

(VIII 77)

Las leyes de Indias están montadas sobre este principio de la exclusión en América de toda otra raza y creencia que la española [...]

(VIII 77)

Para precaverlos de los embates de las industrias extranjeras, como el jardinero protege de la inclemencia las plantas nacientes, creándoles una atmósfera ficticia, la madre patria sustrajo sus colonias al contacto del mundo.

(XII 66)

[...] la miseria mental de España arranca del aislamiento en que nos.puso toda una conducta cifrada en el proteccionismo inquisitorial que ahogó en su cuna la Reforma castiza e impidió la entrada a la Europa.

(Unamuno)

intolerancia:

Pero si la intolerancia es una propensión de los pueblos y los hombres poco educádos en el uso de la libertad, entre los pueblos españoles tiene todavia un grado de intensidad que haria peligroso toçar intempestivamente esta cuerda.

Cuando la España salvó de este peligro ["si el islamismo triunfaba..."] la intolerancia quedó no obstante, en la médula de los huesos de todo el pueblo

xenofobia:

Asi nos educaron para sobrellevar sin murmurar el bloqueo continental en que estuvieron las costas americanas durante tres siglos, en que no oimos hablar de los extranjeros sino como de unos monstruos, herejes y condenados [...]

(l 229) 
Así la España, por odio a los extranjeros, se quedó encerrada en su Penísula.

El odio a lo extranjero de los españoles, es la clave de toda su historia, de sus calidades heroicas, de su aislamiento de la Europa y de su atraso.

La España peleó 700 años con los árabes, y por religión y por patriotismo, aborreció de muerte todo lo que era extranjero.

La España peleó con los árabes, y por religión y por patriotismo, aborreció de muerte todo lo que era extranjero. (IV 77)

[La España] empezó a arrancarse uno a uno los miembros que no animaban la pura sangre española; expulsó de su suelo toda la población española de estirpe judía, no obstante que con ella se iban el dinero y el comercio, con sus banqueros y negociantes; expulsó toda la población española de estirpe árabe no obstante que con ella se despojaba de su industria, de sus fábricas y de sus mejores agricultores.

(XXIII 7)

$Y$ aún del idioma español como rémora:

A las causas generales $[\ldots]$ debe todavia añadirse esta rémora que el idioma opone a la instantánea trasmisión de las ideas útiles y de las aplicaciones prácticas que de ellas hacen los pueblos que nos llevan la delantera

(XII 244)

Es la lengua de Cervantes un viejo reloj rouillé. (LI 223)

Sus condenas encontraron finalmente el emblema adecuado: Rosas. La manera más categórica de simbolizar su rechazo de esa España fue la de encarnarla en el tirano, razón primordial de su lucha: Rosas, "hijo legitimo de la vieja España", quien mandara "bajo las penas más severas, que no se enseñase en las escuelas y colegios públicos y privados otra letra que la española", "un bárbaro [...] que ha querido realizar en la República Argentina lo que Felipe II realizó en España", "la inquisición política de la antigua España personificada"; en resumen: "la España se ha alzado en mi pais y ha restablecido todo lo que la revolución quería destruir: despotismo, inquisición, ignorancia, bàrbarie". (IV 82)

Es necesario decir que la mayoría de las acusaciones y reproches graves que Sarmiento tiene para con España provienen de las ocho cartas que dirigiera al Sr. Rafael Minvielle (y publicara en La Gaceta del Comercio de Santiago de Chile) en respuesta a una anterior del mismo, en 1843 (IV 54-85). Tras la carta de éste, Sarmiento se sintió herido y ofendido, y ello explica la vehemencia de sus respuestas. Hay un párrafo de Minvielle que Sarmiento reproduce; su comentario merece detenernos por su permanente actualidad. Decia Minvielle:

No concluiré esta carta, sin recordar cuál era su posición y la de todos sus desgraciados compañeros, hace dos años, y cuál es ahora. Entonces todos eran compadecidos y aún estimados; 
ahora son mirados en general como unos parias. Esta metamorfosis la atribuyen todos, hasta los que son sus inocentes víctimas, al carácter impetuoso de unos pocos, al desenfado con que siempre emiten sus opiniones, al desprecio con que miran a todo el mundo, desprecio que se ve en todos sus escritos. en todos sus actos, hasta en la sonrisa que alguna vez asoma en sus labios. $Y$ no basta a rehabilitarlos en la opinión, la honradez y la cordura con que los más se conducen en la sociedad.

(IV 73)

Reconozcamos la franqueza, y aún la aspereza, del párrafo de Minvielle. Por eso, es admirable este otro de Sarmiento, en un doble aspecto: el carácter de los argentinos y el de los emigrados en general. En relación con el primero, responde Sarmiento:

Si usted pregunta a todo Santiago, si es cierto lo que se contiene en los párrafos citados, le dirán a usted unánimemente que es cierto todo. Si se lo pregunta a mis amigos, le dirán que es muy cierto; a los argentinos, que es igualmente cierto; si a mi mismo, le diré una y mil veces que es cierto, añadiendo tan solo que escritor alguno, ni aun adversario, habria pintado en caracteres de más alto relieve una verdad tan sentida por todos, y que usted me recuerda con el laudable fin de que me aproveche del aviso, para no extraviarme más y más. Doy a usted por ello las más expresivas gracias.

y todavía agrega:

¿Y creerá usted, señor Minvielle, que asi como usted ha tenido ocasión, con motivo de la Memoria sobre ortografia, de hacer pintura tan exacta, pero tan moderada, yo también he hallado que todo esto tiene puntos de contacto con la España y usted?.

(IV 74)

Respecto del segundo, después de hacer algunas consideraciones sobre la tradicional xenofobia de los pueblos hispánicos, dice Sarmiento en líneas que conviene reproducir in extenso:

Pero existen, señor Minvielle, circunstancias que no están en nuestras manos evitar y que influyen poderosamente en la posición de los hombres. Una de ellas es pertenecer a una emigración. Los emigrados son objeto de compasión para todos los pueblos del mundo, mientras que necesitan de la benevolencia hospitalaria de sus huéspedes. Pero este mismo sentimiento suele cambiarse en animadversión cuando las emigraciones son numerosas, se prolongan demasiado y se componen de individuos de todas las clases. Una emigración toma entonces a los ojos de sus huéspedes el viso de una nación, y la nacionalidad, ese sentimiento $\tan$ noble $y \tan$ profundamente arraigado en el corazón del hombre, es esquiva siempre y descontentadiza. A su turno este mismo sentimiento se exalta en los emigrados con el aislamiento y la ausencia de la patria. Simpatizan entre si en afec- 
ciones $\theta$ intereses y toman efectivamente el aspecto de una sociedad embutida en otra extraña con la que a veces se ponen en pugna, mirándose una y otra con preocupación, y casi siempre bajo un punto de vista falso. Una falta, una indiscreción cometida por uno de aquellos, recae sobre todos los demás; y aunque la razón esté diciendo que esto no es junto, el corazón se deja arrastrar y se hace parcial sin quererlo.

Esto es común, señor Minvielle, a todas las emigraciones de todos los países y de todos los tiempos. Los hombres que forman parte de una emigración tienen, pues, que sufrir las consecuencias de su posición, y no pocas veces por sus hechos son el blanco de la animadversión nacional, aunque esos mismos hombres, si como individuos se acercan a uno de los hijos del pais, si le exigen un servicio, pueden estar casi seguros de obtenerlo lo mismo que cualquiera otro, porque estas prevenciones nacionales, no se ceban por lo general en las personas tomadas aisladamente.

(IV 75)

¿Podria darse mayor actualidad, frente a lo que hoy sucede, con los emigrados chilenos, bolivianos y paraguayos que entran en Argentina, y los de diversos paises que entran y han entrado en los paises de Europa?

Sería superfluo intentar un balance de elogios y reproches. Máxime cuando la mayoría de las cualidadés que Sarmiento pondera tienen verdadero sentido referidas a un individuo concreto (honradez, sobriedad, hidalguia...) mientras que las negativas constituyen primordialmente un conjunto de juicios extraídos de consideraciones históricas, políticas o filosóficas más abstractas y colectivas (fanatismo, censura, atraso, letargo...). Sin duda, para Sarmiento España era más una idea (que combatia) que un pueblo (del que se sentía parte).

En fin, lo que rechazaba con vigor era la obligada intermediación de España, entre Europa y América.

Sin tratar de mirar en menos los esfuerzos que el naciente ingenio español hace hoy por elevarse y desplegar sus alas, no nos arredraremos de decir que la influencia del pensamiento de la península será del todo nula entre nosotros; y que teniendo alli que alimentarse y. tomar sus formas del extranjero, no se nos podrá exigir cuerdamente que recibamos aquí la mercaderia después de haber pagado sus derechos de tránsito por las cabezas de los escritores españoles. En el comercio de las letras, como en el de los artefactos, tenemos comercio libre, y como los españoles, importaremos de primera mano (...)

[...] mientras la España moderna [...] se ha dado vuelta hacia la otra parte de la Europa y trabaja por civilizarse y salir de la barbarie, nosotros los americanos todos permanecemos dados vuelta hacia la España, para que ella nos dé sus rezagos, los harapos viejos que está botando. Por eso es que he examinado tan minuciosamente en mi Memoria lo que es la librería española, 
no con declamaciones, sino tomando los catálogos de libros de nuestras librerias, y apuntando dónde han sido impresos, y por qué autores han sido escritos. Todo esto para inducir a los que lean aquel opúsculo y tengan que ver con la instrucción, a imitar a la España, a darse vuelta completamente hacia las otras naciones de Europa, a poner la cara hacia donde los españoles la han puesto, y no hacia las espaldas de éstos. los españoles:

La intermediación, sin embargo, parece ser un sueño permanente de

Asi España, al ingresar en la Comunidad Europea, lejos de sentirse por ello extrañada de Hispanoamérica renunciando a sus vínculos de esencial afinidad, entiende al contrario que le corresponde servir como puente entre los dos continentes; y en consecuencia ha mostrado su disposición activa a mediar, siempre que fuere requerida a hacerlo, en favor de los intereses de los pueblos hispánicos en cuantos lugares y cuantas oportunidades haga falta. (Francisco Ayala, "EI Descubrimiento de América, hoy", en La Nación, $17 / 11 / 91)$

Hay rigor, aspereza y vehemencia en el antiespañolismo de Sarmiento. No parece conveniente -ni aún conmemorativamente- dar una versión ad usum Delphini. Hay que verlo en sus textos, con toda su crudeza. Lo cual no excluye que, a la hora del balance final, veamos un conflicto latente pero visceral en Sarmiento, conflicto que otros hombre han padecido entre la honestidad intelectual y una estirpe que pugna de modo subterráneo e inconsciente, más allá del derecho y la razón. En esa oscura lucha entre el atavismo y la inteligencia, en Sarmiento ha prevalecido siempre la segunda.

Puede haber en el alegato sarmientino intemperancia, arbitrariedad o exceso. Pero no hay mezquindad, ni especulación, ni insidia. Debe ser dificil para un español leer a Sarmiento sin irritación. Pero esa lectura exasperada es la que siempre han hecho los hombres que han encontrado en los grandes autores el fermento, la levadura necesaria para un examen apasionado, para un análisis profundo o una revisión esencial de las propias circunstancias.

¿No es esa misma revisión -nos permitimos la pregunta- la que ha llevado al agiornamento (como se oye decir) de la España actual? ¿al mismo replanteo, en el fondo, de la historia, del conocimiento, del quehacer, es decir, de la realidad social, económica y cultural española que tantos desvelos y propuestas originara en tan ilustres, probos y honrosos españoles como lo fueron Saavedra Fajardo, Larra, Pi y Margal, Unamuno, Costa, Ortega y tantos hombres de ciencia, de letras y de acción de nuestros días.

Si hubiese vivido cuatro años más, Sarmiento habría asistido a las conmemoraciones del IV Centenario del Descubrimiento de América. ¿Y cuáles habrian sido sus juicios si hubiese asistido hoy a las de $V$ Centenario? 
En la controversia actual -Descubrimiento de América o Encuentro de Culturas, Día de la Hispanidad u Holocausto del Indio- Sarmiento no habría adherido ni a la excelsitud de la Madre Patria ni a la reivindicación del Indígena, porque tampoco sentia al indio como ancestro. Para los tradicionalistas y conservadores, Sarmiento era un insano furioso, un hidrófobo liberal; para los americanistas e indigenistas, es un representante de la aristocracia colonial, de la élite criolla argentina. Raimundo Lida lo decia muy bien: "Para el jacobino, Sarmiento resulta demasiado consenvador y para el reaccionario, demiasiado jacobino". (4) (El caso es recurrente: ¿no le sucedía lo mismo a Camus, entre argelinos y franceses?). Para Sarmiento, la clave -y valor- de nuestra nueva sociedad estaba en el crisol de razas. Sabida es la importancia y lugar que asignó a la inmigración. Habria de ser Ricardo Rojas quien, varias décadas después, integrara ésta con el español y el criollo, $y$, añadiendo el indio. propusiera la síntesis de nuestra identidad (5). Sarmiento sacude el yugo de una sola tradición, pretende universalidad. Borges lo advierte y lo pondera: "Sabe que nuestro patrimonio no debe reducirse a los haberes del indio, del gaucho y del español; que podemos aspirar a la plenitud de la cultura occidental, sin exclusión alguna". (Prólogo de Recuerdos de Provincia).

El antiespañolismo de Sarmiento es un tema insoslayable. Cada crítico lo ha visto a su manera. Rojas, afirmando que "Sarmiento es, como San Martín, un hombre muy español por su origen y su índole, aunque parezca antiespañola su actitud de reformador", lo explicaba de este modo: "hubo un Sarmiento hispanófilo, no porque fuera un simple veleidoso, capaz de frivolas contradicciones, sino porque él miró con encono a la España teocrática y dinástica, y con amor de cosa propia, a la España republicana y popular" (6). Ralmundo Lida advertía con razón que a pesar de la extremosidad, y aun falibilidad, de sus ideas, Sarmiento tenia "el don de tocar en los puntos nerviososo de la historia de España". Decia Lida: "Podrá Sarmiento exagerar hasta la injusticia la crítica de lo español, pero nada hay más raigalmente español que esa crítica" (7).

Ni esta interpretación, ni la anterior, ni la siguiente, serian sin embargo compatibles con la más severa e intransigente de Luis Franco, quien sostiene que Sarmiento, como Marti "Acusaron desde el principio un perfil lo menos español posible, y nada tuvo España ni Europa ni la otra América que se les pareciese" (8).

También Dardo Cúneo vio la paradoja de un Sarmiento antiespañol a la española. Observa que el anti-hispanismo fue un lugar común en nuestra generación del 37. "Alardear de anti-españolismo es credencial generacionista" (9). Esa crítica también fue lugar común en la generación española del 98. Por eso Unamuno acepta las acusaciones y reproches de Sarmiento: "No los responde dice Cúneo- . Más: los comprende, como que todos los juicios del argentino se reproducirán en el lenguaje de los hombres de la generación española que enrola a Unamuno".

Pero Cúneo, Lida, Rojas, pueden ser sospechosos de fraternidad americana. No asi Unamuno, que reconocia con franqueza: 
Siempre que leo los ataques de Sarmiento a España y las cosas españolas, y sus excitaciones a sus paisanos para que se desespañolizaran, se me viene a las mientes aquel sabido verso de Bartrina, que dice: "y si habla mal de España, es español". Porque, en efecto, Sarmiento hablaba mal de España en español, y como los españoles lo hacemos: maldiciendo de nuestra tradición las mismas cosas que de ella maldecimos los españoles y de la misma manera que las maldecimos. Basta leer en sus Viajes el relato del que hizo a España en 1846, y se verá cuán hondo y ardiente españolismo trasciende de sus severos juicios respecto a nuestros defectos. Su censura no era la censura que suele ser la de los extranjeros, que ni penetran en nuestro espíritu ni aprecian nuestras virtudes ni nuestros vicios; su censura era la de un hombre de poderosísima inteligencia que sentía en si mismo lo que en nosotros veía. y que penetraba con amor fraternal en nuestro espiritu.

("Algunas consideraciones sobre la literatura hispano americana", en Ensayos, Aguilar, 1951, t.l., P.867).

Es por eso que para Unamuno, Sarmiento era "el más español acaso de todos los pensadores y escritores sudamericanos". Y por lo que, finalmente, afirmaba: "Si algún criollo ha cultivado la manía de atribuir las deficiencias de su casta -o las que le parecían tales, aún sin serlo- a la herencia española., fue el que en el campo de la literautra marcó la mayor genialidad, el escritor americano de lengua española que hasta hoy se nos ha mostrado como el más robusto y poderoso ingenio y más fecunda originalidad". 


\section{NOTAS}

(1) Todas las citas corresponden a la edición de las Obras de A. Belin Sarmiento.

(2) Sarmiento tenía predilección por la novela y la defendia, en tiempos en que era fácilmente denostada. Se ha referido al género en múltiples ocasiones. Véase, particularmente, "Las novelas" (XLVII 159).

(3) Paul Verdevoye ha tratado exhaustivamente este asunto. Véase "Un mismo tema tradicional, tratado por. Sarmiento. J. López Silva y Nicolás de las Llanderas... y A. Camus" en Homenaje a Ana Marla Barranechea, Madrid, Castalia, 1984. p. 557.

(4) R. Lida, "Hacia el humor de Sarmiento", en Sarmiento: Centenario de su muerte, Buenos Aires, Academia Argentina de Letras, 1988, p. 276.

(5) Un personaje de Sabato (que se llama curiosamente Sabato) enuncia su "Teoría sobre la nueva Argentina": "Resultante de tres grandes pueblos: españoles, italianos y judios. Si lo pensás un poco, verás que nuestras virtudes y nuestros defectos vienen de ahi". (Abaddón, Bs. As., Sudamenricana, 1974, p. 212)

(6) Ricardo Rojas, El profeta de la pampa, Bs. As., Losada, 1945, p. 283.

(7) R. Lidia, ibid., p. 268.

(8) Luis Franco, Sarmiento y Marti, Bs. As., Lautaro, 1958, p. 440

(9) Dardo Cúneo, Las dos generaciones", en Sarmiento y Unamuno, Bs. As., Pleamar, 1963, p. 140. 